\title{
Atom Probe Tomography Investigations of Microstructural Evolution in an Aged Nickel Superalloy for Exhaust Applications
}

\author{
HAZEL GARDNER, STELLA PEDRAZZINI, JAMES O. DOUGLAS, \\ DIDIER DE LILLE, MICHAEL P. MOODY, and PAUL A.J. BAGOT
}

\begin{abstract}
The formation and evolution of nanoscale $\gamma^{\prime \prime}\left(\mathrm{Ni}_{3}(\mathrm{Nb}, \mathrm{Ti}, \mathrm{Al})\right)$ precipitates formed during thermal aging in the nickel superalloy Inconel 625 has been characterized using Atom Probe Tomography. The onset of $\gamma^{\prime \prime}$ precipitation has been found to occur after only one hour, markedly shorter than the aging time reported in the current literature. Evolution of precipitate composition and morphology during aging has been analyzed, and the potential onset of the $\gamma^{\prime \prime} \rightarrow \delta\left(\mathrm{Ni}_{3}(\mathrm{Nb}, \mathrm{Mo}, \mathrm{Cr}, \mathrm{Fe}, \mathrm{Ti})\right)$ transformation after long aging times is discussed.
\end{abstract}

https://doi.org/10.1007/s11661-018-5098-x

(C) The Author(s) 2019

\section{INTRODUCTION}

THE development of nickel superalloys has been driven by the need for corrosion-resistant materials with excellent high-temperature performance for use in gas-turbine engines for aircraft propulsion and power generation. The first jet engines were made from steel but as engine efficiency increased, so too did engine operating temperatures. New materials were required to make turbine blades able to withstand the higher temperatures and corrosive jet engine environment. Nickel superalloys were developed to fulfill these requirements, and have been extensively used by aerospace industries since $1929 .^{[1]}$

The unique combination of high-temperature strength and excellent corrosion resistance means that use of nickel superalloys is not limited to the aerospace sector but is in fact applicable in a wide range of extreme environments. For example, Inconel 625 is a nickel superalloy originally designed for high-strength steam piping for supercritical steam power plants. ${ }^{[2]}$ However, in recent years, the alloy has been used to make exhausts for Formula 1 class racing engines. ${ }^{[3]}$

HAZEL GARDNER, JAMES O. DOUGLAS, MICHAEL $P$. MOODY, and PAUL A.J. BAGOT are with the Department of Materials, University of Oxford, Parks Road, Oxford OX1 3PH, UK. Contact e-mail: hazel.gardner@materials.ox.ac.uk STELLA PEDRAZZINI is with the Royal School of Mines, Imperial College London, Exhibition Road, London SW7 2AZ, UK. DIDIER DE LILLE is with the Good Fabrications Ltd., Long Crendon, Aylesbury HP18 9BA, UK.

Manuscript submitted August 28, 2018.

Article published online January 18, 2019
The excellent corrosion resistance of Inconel 625 enables exhaust tubings to withstand the corrosive environment created by the exhaust gases. Tight fuel allowances in the sport mean that in order to reach competitive speeds, an energy recovery system (ERS) must now be used in conjunction with the internal combustion engine (ICE) ${ }^{[4]}$ This increases the thermal efficiency of the power unit (ERS + ICE) to $\sim 50$ pct. The high-temperature behavior of Inconel 625 must as a result be well understood to enable the exhaust system to cope with the rising heat loads.

Nickel superalloys owe their corrosion resistance and high-temperature strength to the careful choice of alloying additions. For example, aluminum, chromium, and molybdenum are added to improve corrosion resistance. Niobium also enhances corrosion resistance, ${ }^{[5]}$ while titanium degrades it. ${ }^{[6,7]}$ In the case of Inconel 625 , formation of the ordered $\gamma^{\prime \prime}$ strengthening phase is promoted by the addition of niobium and aluminum. ${ }^{[8]}$ This coherent $\gamma^{\prime \prime}$ phase has a $\mathrm{DO}_{22}$ crystal structure and can more than double the yield stress. ${ }^{[9]} \gamma^{\prime \prime}$ $\left(\mathrm{Ni}_{3}(\mathrm{Nb}, \mathrm{Ti}, \mathrm{Al})\right)$ forms in preference to $\gamma^{\prime}\left(\mathrm{Ni}_{3} \mathrm{Al}\right)$ in alloys with lower aluminum and titanium content such as Inconel $625 .^{[10]}$

Aging controls the size, volume fraction, and morphology of the $\gamma^{\prime \prime}$ precipitates, which in turn determines the mechanical properties of the alloy. Although the exhaust is initially in a solution-treated state, it operates between $600{ }^{\circ} \mathrm{C}$ and $1000{ }^{\circ} \mathrm{C}$ which means that the microstructure evolves throughout service.

Despite the importance of the $\gamma^{\prime \prime}$ phase in governing the mechanical properties of Inconel 625, the aging time and temperature at which $\gamma^{\prime \prime}$ precipitates first form are not well understood. Multiple time-temperature-transformation (TTT) curves have been proposed for the 
Inconel 625 system, ${ }^{[1-13]}$ but there is disagreement between these curves. In particular, the position of the $\gamma^{\prime \prime}$ nose, which is the point on the TTT curve at which $\gamma^{\prime \prime}$ first starts to form, varies between studies from 2 to 10 hours. ${ }^{[11-13]}$

It is likely that an increase in resolution of the characterization techniques used for phase identification (from optical microscopy ${ }^{[12]}$ to Field Emission Gun Scanning Electron Microscopy (FEG SEM ${ }^{[13]}$ ) has led to the nose of the $\gamma^{\prime \prime}$ curve being shifted to shorter aging times. Microhardness measurements made by Suave et $a l^{[14]}$ support this hypothesis, suggesting that $\gamma^{\prime \prime}$ precipitation may occur after aging for as little as 0.5 hours at $650{ }^{\circ} \mathrm{C}$. This work uses the high spatial resolution and chemical sensitivity of atom probe tomography (APT) ${ }^{[15]}$ to determine the onset of $\gamma^{\prime \prime}$ precipitation to a higher degree of precision.

Furthermore, $\gamma^{\prime \prime}$ precipitate composition is not well-defined. Work by Floreen et al. ${ }^{[11]}$ reports the precipitate composition as a range, $\mathrm{Ni}_{3}(\mathrm{Nb}>0.5 \mathrm{Ti}<$ $0.5 \mathrm{Al}<0.5)$. However, while transmission electron microscopy (TEM) has sufficient spatial resolution to image such nanoscale precipitates, it is challenging to obtain fully quantitative compositions using TEM-Energy Dispersive X-ray Spectroscopy (EDS). ${ }^{[1,17]}$ Thus, a secondary goal of this research was to use APT to provide quantitative $\gamma^{\prime \prime}$ compositions, as well as studying the evolution of both morphology and composition of the precipitates during aging.

\section{EXPERIMENTAL METHODS}

Inconel 625, originally melted by Special Metals Corporation (SMC), was provided by Good Fabrications Ltd. Additional Inconel 625 was sourced from Goodfellow Cambridge Ltd (GCL). The SMC strip was cold rolled to deep drawing quality and subsequently pickled and annealed at $1040{ }^{\circ} \mathrm{C}$ in a continuous furnace, whereas the GCL sheet was annealed and tempered. The heat treatments for both materials were such that no $\gamma^{\prime \prime}$ precipitates were expected to form in the as-received material, and none were found upon APT analysis. The nominal compositions of the as-received material are reported in Table I.

The Inconel 625 strip was cut into matchsticks using a Buehler Isomet 4000 saw. The matchsticks were $\sim 20 \mathrm{~mm}$ in length, with a square cross section of side length $\sim 0.7 \mathrm{~mm}$. Samples were then aged in a vacuum tube furnace for 1 hour at $650 / 700 / 750{ }^{\circ} \mathrm{C}$ to investigate the onset of $\gamma^{\prime \prime}$ precipitation, and for $10 / 100 / 1000$ hours at $650{ }^{\circ} \mathrm{C}$ to investigate the evolution of $\gamma^{\prime \prime}$ precipitates during aging. Matchsticks were heated to the respective aging temperatures at a rate of $1200^{\circ} \mathrm{C}$ per hour to minimize uncertainty in aging time, and a vacuum of $10^{-6}$ mbar was maintained throughout.

Specimens were prepared for analysis by APT via electrochemical polishing, ${ }^{[15]}$ using a solution of $10 \mathrm{pct}$ perchloric acid in solution in 90 pct acetic acid and an applied voltage of $25 \mathrm{~V}$. A second stage of polishing was carried out to refine the tip shape, using a solution of
2 pet perchloric acid dissolved in 98 pet butoxyethanol, with an applied voltage of 20 to $25 \mathrm{~V}$.

Specimens were analyzed using a Cameca LEAP 3000X HR system and a Cameca LEAP 5000XR (Department of Materials, University of Oxford.). The LEAP 3000X HR and LEAP 5000XR have detector efficiencies of $\sim 37$ and $\sim 52 \mathrm{pct}$, and laser wavelengths of $532 \mathrm{~nm}$ and $355 \mathrm{~nm}$, respectively. During APT experiments, all specimens were cryogenically cooled to $50 \mathrm{~K}$ to $55 \mathrm{~K}$, within a UHV analysis chamber pumped to $<4 \times 10^{-11}$ Torr. Specimens were run in laser mode at a pulse frequency of $200 \mathrm{kHz}$ and at a target evaporation rate between 0.4 and 1 pct. A laser-pulse energy between 0.3 to $0.5 \mathrm{~nJ}$ and 0.03 to $0.05 \mathrm{~nJ}$ was used on the LEAP 3000 and LEAP 5000, respectively. The laser powers were selected to ensure power density remained comparable between the two instruments.

Hardness tests were performed using a Wilson Wolpert microhardness indenter and processed using the analysis software Minuteman. The dwell time was 10 seconds and the applied load was $0.5 \mathrm{~kg}$. A minimum of ten measurements were made across the length of the sample, keeping away from the specimen edge, to ensure representative sampling. Each test was performed sufficiently far (a distance of 2.5 times the width of the indent) from the previous to prevent interaction of plastic zones. ${ }^{[18]}$

\section{RESULTS}

\section{A. Onset of Precipitation}

Figure 1 compares atom maps of solution-treated and aged Inconel 625 ( 1 hour at $650^{\circ} \mathrm{C}, 700^{\circ} \mathrm{C}$ and $750{ }^{\circ} \mathrm{C}$.) The atom maps display only nickel, titanium, and niobium ions for visual clarity. The precipitates are highlighted using a 4.5 at. pct $\mathrm{Nb}+\mathrm{Ti}$ isoconcentration surface and are identified as $\gamma^{\prime \prime}$ since they are enriched in nickel, niobium, and titanium. It can be seen from Figure 1 that nanoscale $(\sim 5 \mathrm{~nm})$ precipitates have formed after aging for only 1 hour at $700{ }^{\circ} \mathrm{C}$ and $750{ }^{\circ} \mathrm{C}$, whereas the alloying elements remain in complete solid solution in the sample aged for 1 hour at $650{ }^{\circ} \mathrm{C}$. This is supported by the nearest neighbor distributions ${ }^{[15]}$ for this sample, shown in Figure 2(b).

The agreement between the expected distributions for a random solid solution (shown with dotted lines on Figure 2(b)) and the measured distributions of titanium and niobium atoms (shown in solid lines on Figure 2(b)) suggests that there is no clustering in the sample aged for 1 hour at $650{ }^{\circ} \mathrm{C}$. However, deviation of the measured distribution from the randomized distribution can be seen in the plots in Figure 2 for all other aging conditions, suggesting that clustering of niobium and titanium atoms is occurring at longer aging times and higher aging temperatures.

\section{B. Evolution of Precipitates as a Function of Aging Time}

Samples of Inconel 625 were aged at $650{ }^{\circ} \mathrm{C}$ for 10 , 100, and 1000 hours. Figure 3(a) shows the atom maps 
Table I. Nominal Compositions of the As-Received Inconel 625 Material

\begin{tabular}{lcccccccccccc}
\hline & \multicolumn{10}{c}{ Atomic Percent } \\
\cline { 2 - 13 } & $\mathrm{Ni}$ & $\mathrm{Co}$ & $\mathrm{Cr}$ & $\mathrm{Fe}$ & $\mathrm{Mo}$ & $\mathrm{Nb}$ & $\mathrm{Al}$ & $\mathrm{Ti}$ & $\mathrm{Mn}$ & $\mathrm{Si}$ & $\mathrm{C}$ & $\mathrm{S}$ \\
\hline $\mathrm{SMC}$ & $>58.0$ & $<1.0$ & 24.0 & $<5.3$ & 6.0 & 2.0 & $<0.9$ & $<0.5$ & $<0.5$ & $<1.1$ & $<0.5$ & $<0.03$ \\
$\mathrm{GCL}$ & $\begin{array}{l}\text { balance } \\
\text { (Ni }+\mathrm{Co})\end{array}$ & 23.6 & $<5.1$ & 5.3 & 2.2 & 0.5 & 0.3 & 0.3 & 1.0 & $<4.7$ & 0.03 \\
& & & & & & & & & & & & \\
\hline
\end{tabular}

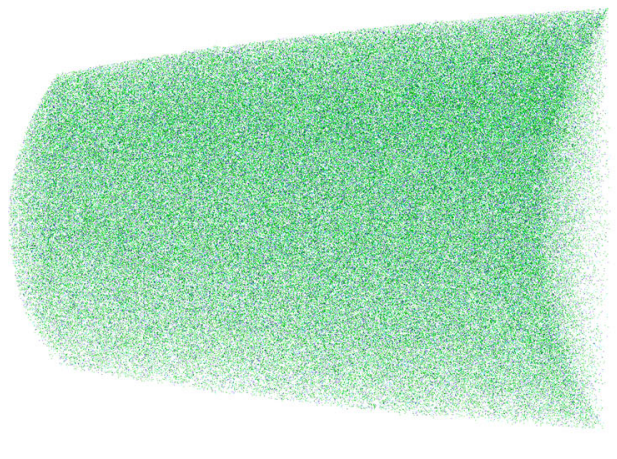

(a)

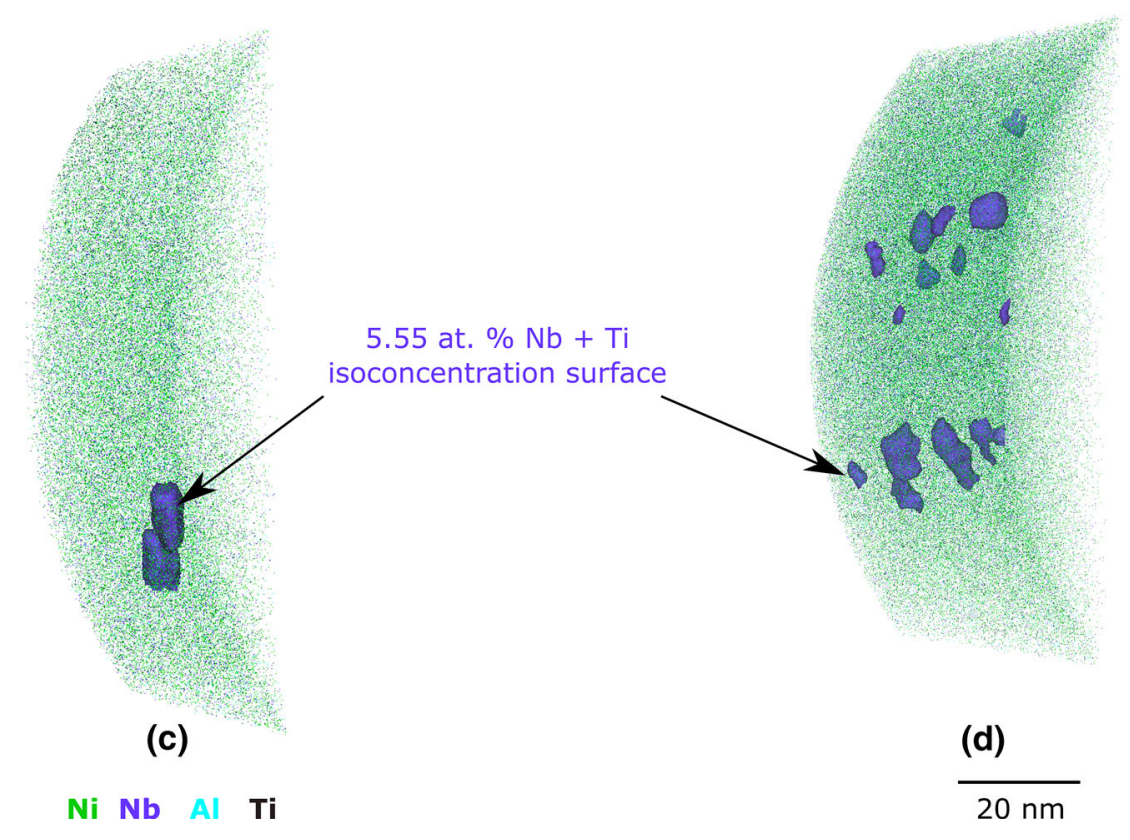

Fig. 1-APT atom maps for the solution-treated, as-received sample $(a)$, and the samples aged for $1 \mathrm{~h} \mathrm{at} 650{ }^{\circ} \mathrm{C}(b), 1 \mathrm{~h}$ at $700{ }^{\circ} \mathrm{C}(c)$ and $1 \mathrm{~h}$ at $750{ }^{\circ} \mathrm{C}(d)$. In all atom maps, only nickel, niobium, aluminum, and titanium atoms have been displayed for clarity (Color figure online).

corresponding to these treatments, with precipitates apparent at all aging times, as highlighted using $\mathrm{Nb}+$ $\mathrm{Ti}$ isoconcentration surfaces. The values chosen for these isoconcentration surfaces (see figure caption) were chosen using the proximity histograms (proxigrams ${ }^{[15]}$ ) in Figure 7. The isoconcentration value was adjusted until the position of the interface, shown by the dotted line in Figure 7, coincided with the point of inflection of the niobium concentration profile on the proxigram. A separate set of isoconcentration surfaces (not shown) was used to select the core of precipitates for compositional analysis, thus avoiding the inclusion of precipitate-matrix interfacial regions. Precipitates initially start off spherical, as seen in Figure 3(a)(i) and then become elongated with increasing aging time. This is reflected in Figure 3(b) since as aging time increases, the 


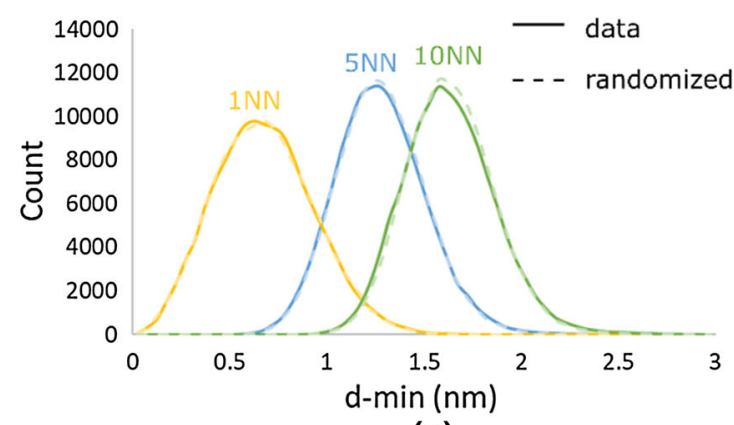

(a)

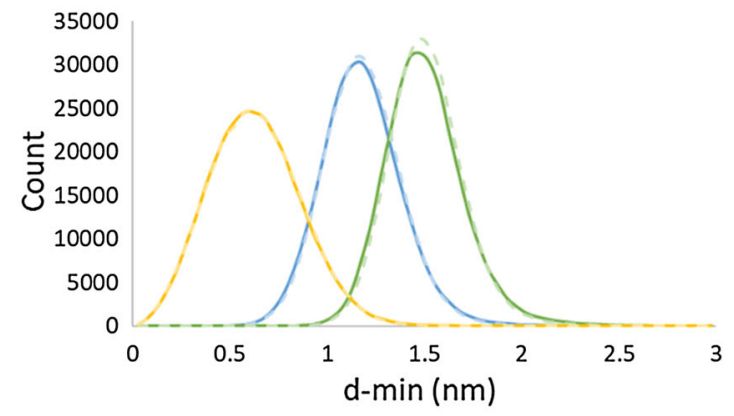

(b)

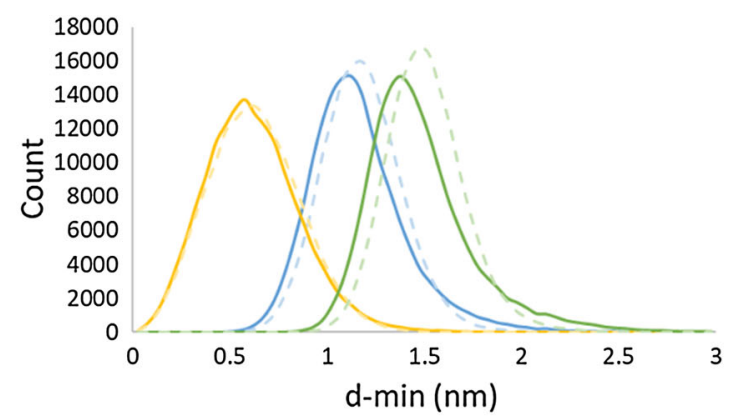

(c)

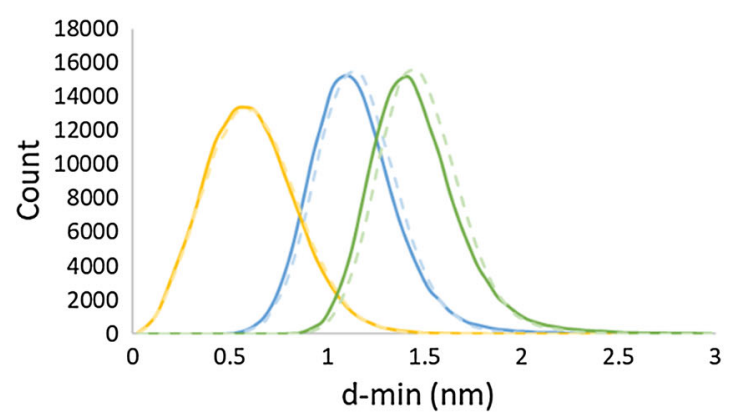

(d)

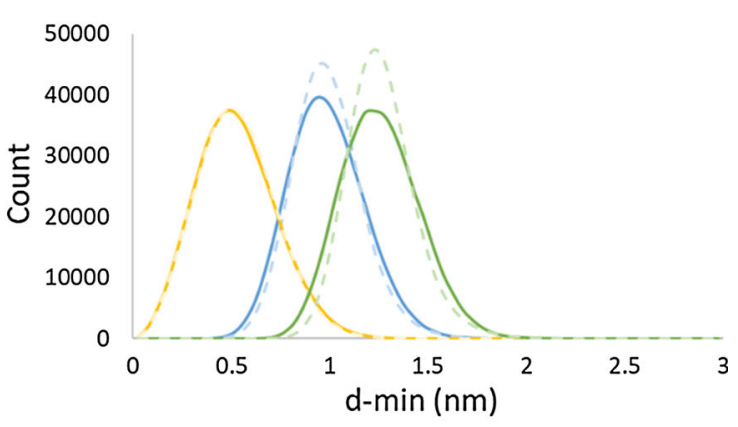

(e)

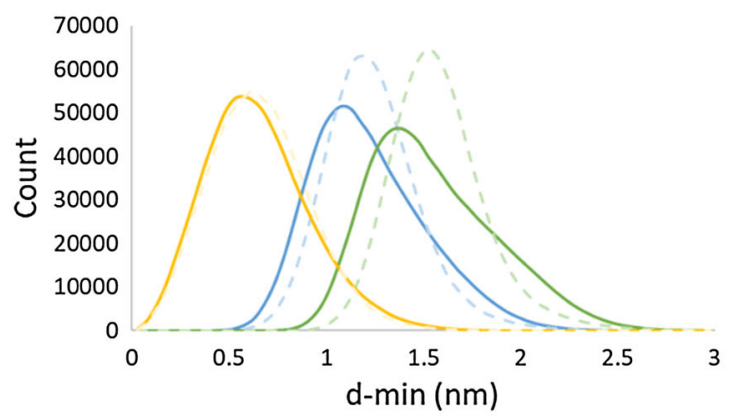

(f)

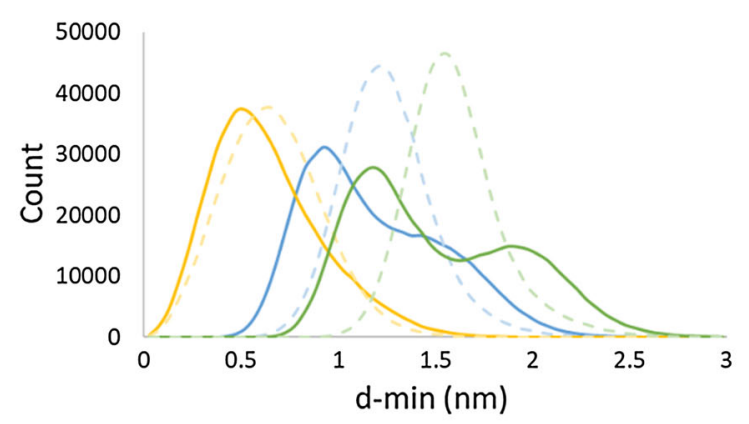

(g)

Fig. 2-Nearest neighbor distance distribution for $\mathrm{Nb}$ atoms for the $(a)$ solution-treated Inconel 625 and the samples aged for $(b) 1 \mathrm{~h}$ at $650{ }^{\circ} \mathrm{C}$, (c) $1 \mathrm{~h}$ at $700{ }^{\circ} \mathrm{C},(d) 1 \mathrm{~h}$ at $750{ }^{\circ} \mathrm{C},(e) 10 \mathrm{~h}$ at $650{ }^{\circ} \mathrm{C},(f) 100 \mathrm{~h}$ at $650{ }^{\circ} \mathrm{C},(g) 1000 \mathrm{~h}$ at $650{ }^{\circ} \mathrm{C}$. For each sample, the order parameter is varied from $1 \mathrm{NN}$ (yellow) to $5 \mathrm{NN}$ (blue) and $10 \mathrm{NN}$ (green). In each case, the dotted line shows the distribution of NN distances that would be expected in a solution of randomly distributed atoms. The solid line shows the distribution of NN distances measured within the APT dataset (Color figure online).

number of precipitates in top right-hand quadrant of the plots decreases, indicating precipitates are becoming less spherical. After long aging times (1000 hours), precipitates become aligned along three distinct directions, with an angle of approximately 90 degrees between them, as can be seen in Figure 4. This 


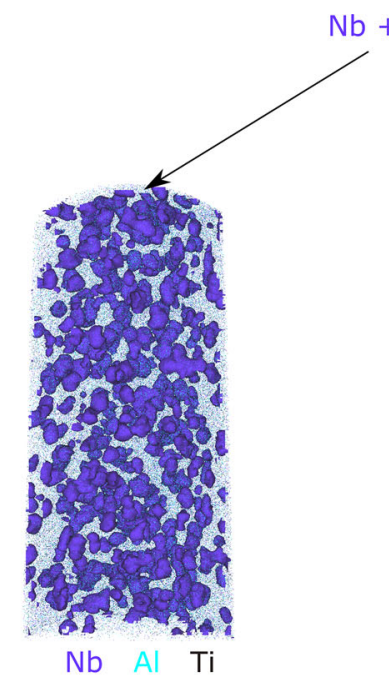

(i)

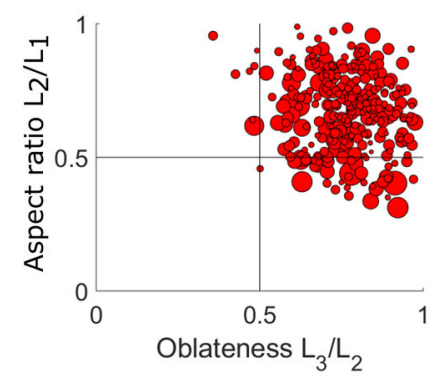

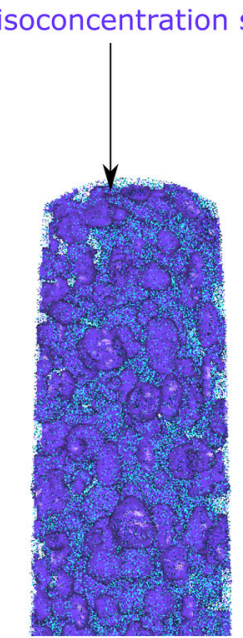

(a)

(ii)



(b)

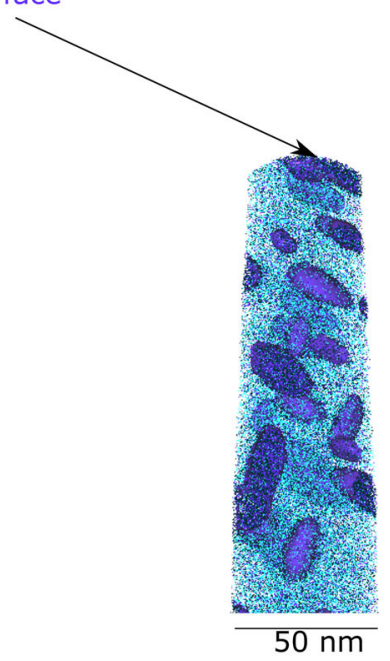

(iii)

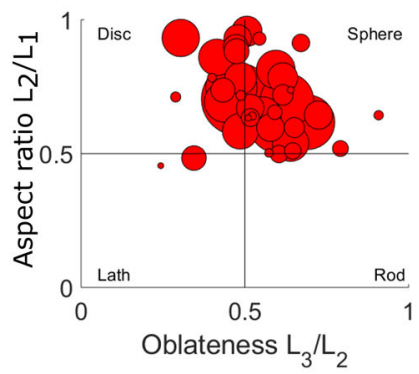

Fig. 3-Atom maps for Inconel 625 samples aged for 10,100 , and $1000 \mathrm{~h}$ at $650{ }^{\circ} \mathrm{C}$ are shown in (a)(i) through (iii), respectively. In (a)(i) and (a)(ii), precipitates are highlighted using 4.5 at. pct $\mathrm{Nb}+\mathrm{Ti}$ isoconcentration surfaces, whereas in (a)(iii), a 4 at. pct $\mathrm{Nb}+\mathrm{Ti}$ isoconcentration surface was used. In each atom map, 20 pct of the $\mathrm{Al}$ and $\mathrm{Nb}$ atoms, and 100 pct of the Ti atoms are displayed for clarity. Plots of precipitate aspect ratio $v s$ oblateness for the samples aged for 10,100 , and $1000 \mathrm{~h}$ at $650{ }^{\circ} \mathrm{C}$ are shown in $(b)(\mathrm{i})$ through (iii), respectively, to indicate change in precipitate morphology. $L_{1}, L_{2}$, and $L_{3}$ are the three axes of the precipitate, where $L_{1}>L_{2}>L_{3}$. A circle is plotted for each precipitate, and the circle size is proportional to the number of ions contained in the precipitate (Color figure online).

alignment is consistent with SEM images of Inconel 625 aged for 1000 hours at $650{ }^{\circ} \mathrm{C}$ in the literature. ${ }^{[13]}$

Closer analysis of the atom probe data taken from the long-term aged samples reveals the partitioning preference of the alloying elements in Inconel 625. APT analysis determined the average concentration of precipitates in this 1000 -hour aged sample to be (in at. pct) $71 \mathrm{Ni}, 15 \mathrm{Nb}$, 5.1 Mo, 4.3 Cr, 2.7 Ti, 1.0 Al, 0.5 Fe. It can be seen from Figure 5 that niobium, titanium, and nickel preferentially partition to the precipitates, whereas chromium, iron, and molybdenum partition to the matrix. The precipitates are assumed with a good degree of confidence to be $\gamma^{\prime \prime}$, based on a combination of their composition, the applied aging conditions, and prior knowledge of the TTT diagrams for the $\gamma-\gamma^{\prime \prime}$ system.

The plots in Figure 5, created using the Lever rule, ${ }^{[19]}$ also provide information about the partitioning preferences of the alloying elements. The Lever rule is as follows:

$$
C_{n}=V_{\gamma^{\prime \prime}} C_{\gamma^{\prime \prime}}+\left(1-V_{\gamma^{\prime \prime}}\right) C_{\gamma},
$$

where $C_{n}$ is the composition of the whole dataset, $C_{\gamma}$ and $C_{\gamma^{\prime \prime}}$ are the compositions of the matrix and $\gamma^{\prime \prime}$ precipitates, respectively, and $V_{\gamma^{\prime \prime}}$ is the volume fraction of the $\gamma^{\prime \prime}$ precipitates. The molar volume of the precipitates and matrix are assumed to be equal. For each element, $C_{n}-C_{\gamma}$ has been plotted against $C_{\gamma^{\prime \prime}} C_{\gamma_{n}}$ creating a linear plot with gradient equal to the $\gamma^{\prime \prime}$ volume fraction.

Elements plotted in the negative- $x$, negative- $y$ quadrant partition to the matrix, whereas elements plotted in the positive- $x$, positive- $y$ quadrant partition to the precipitates. Figure 6(d) compares the Lever rule plots for all three aging conditions and confirms that nickel, titanium, and niobium partition to the precipitates, while the remaining elements partition to the matrix. It can be seen from Figure 6(d) that molybdenum has no strong partitioning preference as aging progresses, although after 100 hours of aging at $650{ }^{\circ} \mathrm{C}$ it appears to switch preference to the matrix instead of the precipitates. The arrows on Figure 6(d) indicate how the precipitate composition evolves with aging time.

The behavior of molybdenum was investigated further by taking proximity histograms ${ }^{[15]}$ to measure the chemistry across the precipitate-matrix interfaces, which are shown in Figure 7. Comparison of the three 


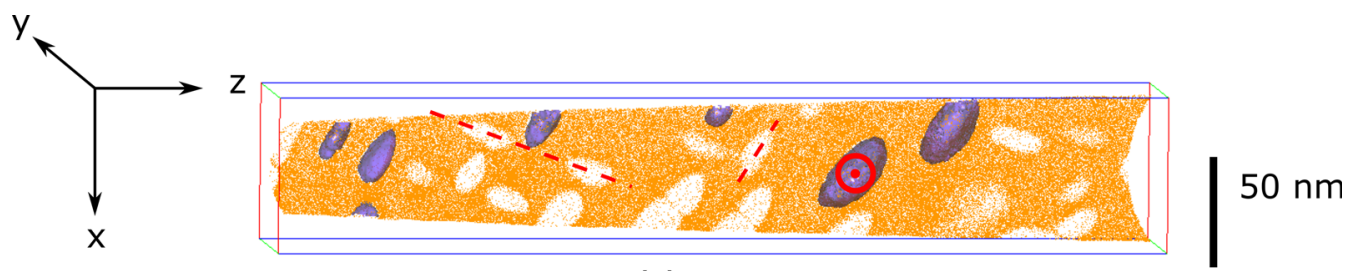

(a)

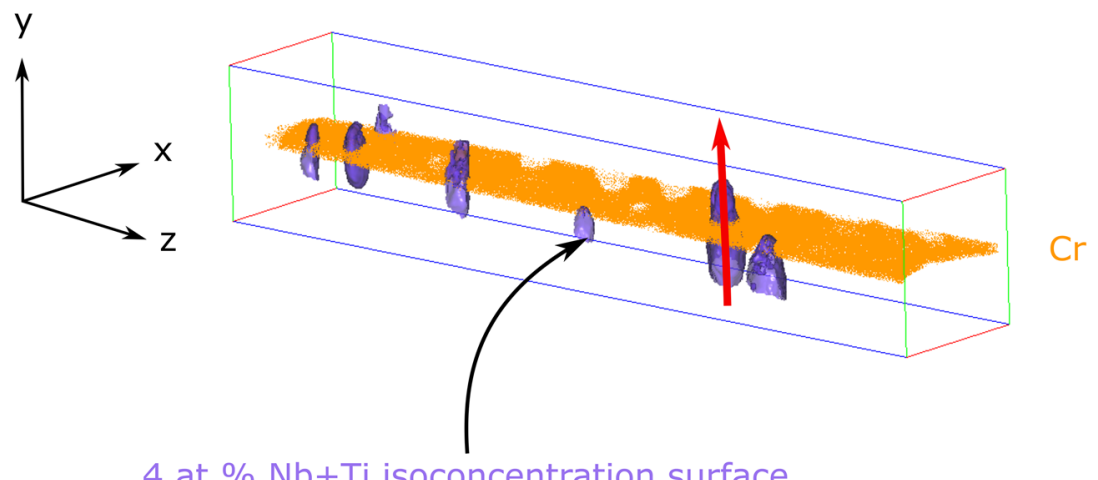

(b)

Fig. 4-Slice through chromium atom map showing orientation of $\gamma^{\prime \prime}$ precipitates in sample aged for $1000 \mathrm{~h}$ at $650{ }^{\circ} \mathrm{C}$. In $(a)$ two approximately orthogonal in-plane precipitate, orientations are indicated by dotted lines while the third orientation is indicated with the circle. In $(b)$, the precipitates aligned along the third orientation can be more clearly seen.

proxigrams reveals segregation of molybdenum to the precipitate-matrix interface in the 1000-hour aged sample, whereas the molybdenum concentration increases smoothly across the interface (from matrix to precipitate) for shorter aging times.

The full evolution of precipitate and matrix compositions with aging time is presented in Table II. As aging progresses, the concentration of nickel and niobium in the matrix becomes slightly depleted to form $\gamma^{\prime \prime}$. This is reflected in the movement of nickel and niobium in the positive $\mathrm{x}$ direction with increasing aging time on the Lever diagrams in Figure 6(d). The concentration of $\gamma$ stabilizers in the precipitates, including chromium and iron, decreases with aging time, as these elements are rejected into the matrix and the precipitates approach a stoichiometry of $\mathrm{Ni}_{3}(\mathrm{Nb}, \mathrm{Ti}, \mathrm{Al})$. This corresponds to a shift in the negative $\mathrm{x}$ direction of chromium and iron in Figure 6(d) as aging progresses.

The volume fractions obtained from the Lever rule plots are shown in Figure 8. It can be seen that volume fraction increases with aging time. The large error bar on the volume fraction measurement for the 10-hour aged sample is a result of the sensitivity of the Lever rule plots to variations in chromium and niobium concentration in particular. Figure 6(a) shows that there was variation in chromium matrix composition for the 10-hour aged sample, which could have occurred due to local fluctuations in heat treatment. Microhardness measurements were also taken for all samples aged at $650{ }^{\circ} \mathrm{C}$, and for a solution-treated sample. These are also shown in Figure 8, revealing a strong positive correlation of hardness with $\gamma^{\prime \prime}$ volume fraction, confirming a strong link between the APT measurements and bulk mechanical properties.

\section{DISCUSSION}

\section{A. Onset of Precipitation}

The APT results of Figure 1 show no apparent precipitates in samples aged for 1 hour at $650{ }^{\circ} \mathrm{C}$; however, in comparison, precipitation of $\gamma^{\prime \prime}$ was observed after only 1 hour of aging at $700{ }^{\circ} \mathrm{C}$. This is markedly shorter than the aging time previously reported for the onset of precipitation in the literature at this temperature. ${ }^{[13]}$ This information has been used to produce an updated time-temperature-transformation (TTT) curve for Inconel 625, which can be seen in Figure 9.

While it is acknowledged that precipitation of $\gamma^{\prime \prime}$ is sensitive to niobium content, ${ }^{[20]}$ the difference in niobium content between the materials used in this study and that used in the study by Suave et al. ${ }^{[13]}$ is small.*

*Average APT-measured composition of SMC material and GCL material were 1.62 at. pct $\mathrm{Nb}$ and 1.60 at. pct $\mathrm{Nb}$, respectively. The reported $\mathrm{Nb}$ composition of the material used by Suave et al. ${ }^{[13]}$ was 1.64 at. pet $\mathrm{Nb}$.

Forming history is also known to affect $\gamma^{\prime \prime}$ precipitation $^{[13]}$ but the material used in both studies was in the as-rolled condition. Thus, comparison of this study with that by Suave et al. in Figure 8 is deemed valid. 


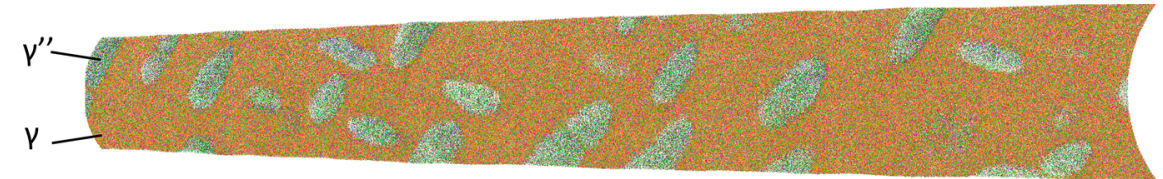

(a)

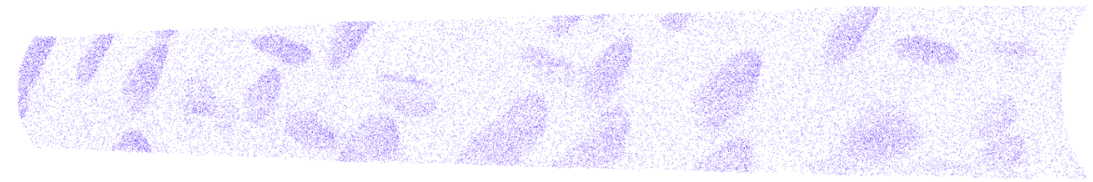

(b)



(c)

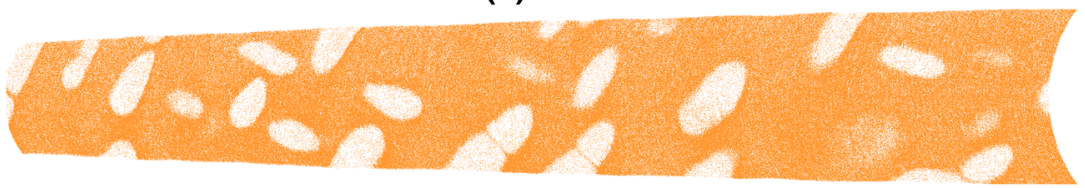

(d)

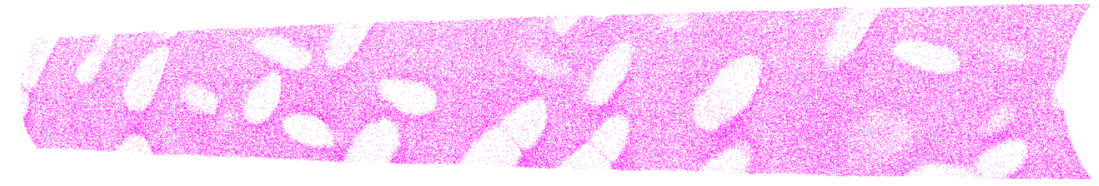

(e)

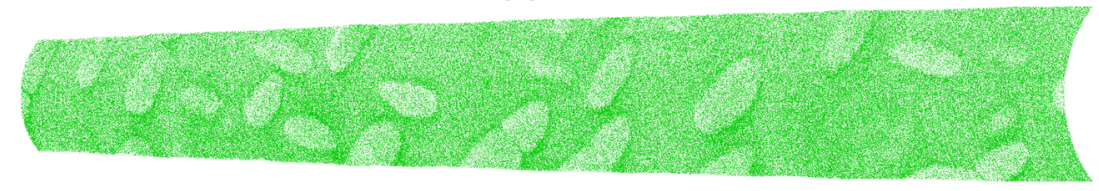

(f)

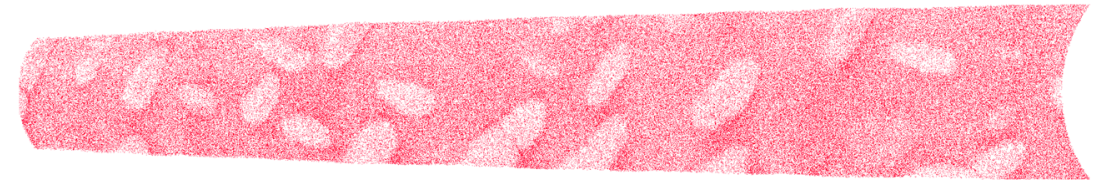

(g)
All ions

$\mathrm{Nb}$

$\mathrm{Ti}$

$\mathrm{Fe}$

$\mathrm{Ni}$

Mo

\section{$50 \mathrm{~nm}$}

Fig. 5-APT atom maps for the sample aged for $1000 \mathrm{~h}$ at $650{ }^{\circ} \mathrm{C}$. (a) Displays all the ions in the dataset, $(b$ through $g)$ displays individual elements separately. Angle between precipitates ranges from 70 to $90 \mathrm{deg}$, which is in agreement with SEM images taken by Suave et al. ${ }^{[13]}$

\section{B. $\gamma^{\prime \prime} \rightarrow \delta$ Transformation}

The composition of the $\gamma^{\prime \prime}$ precipitates that form during aging treatment evolves over time, as shown in Table II. In the current literature, the composition of $\gamma^{\prime \prime}$ is reported as a range: $\mathrm{Ni}_{3}(\mathrm{Nb}>0.5 \mathrm{Ti}<0.5 \mathrm{Al}<0.5)$, which corresponds to (all in at. pet) $75 \mathrm{Ni},>12.5 \mathrm{Nb}$, $<12.5 \mathrm{Ti},<12.5 \mathrm{Al}^{[11]}$ Other than the work done by Floreen et al., ${ }^{[11]}$ there has been little work done in the literature on determining the composition of the $\gamma^{\prime \prime}$ phase. This study has narrowed down these ranges to 67-72 Ni, 14-16 Nb, 1.0-1.1 Al, and 2.6-3.1 Ti. In particular, the values for titanium and aluminum have been significantly refined compared to the overestimated values reported by Floreen et al..$^{[11]}$ Molybdenum $(\sim 6$ at. pct), chromium ( 6 at. pct), and iron $(\sim 0.4$ at. pct) are also present in the precipitates; further work is needed to confirm their particular site preferences.

It is speculated that the rejection of large Mo from the precipitates into the matrix at long aging times could be indicative of the lattice distortion that arises in the $\gamma^{\prime \prime}$ phase prior to the $\gamma^{\prime \prime} \rightarrow \delta$ transformation. ${ }^{[21,22]}$ This hypothesis is supported by proxigram analysis across the precipitate-matrix interface in the 1000-hour aged samples, showing Mo is segregating to the interface. This suggests a loss of precipitate coherency, possibly indicating the start of the $\gamma^{\prime \prime} \rightarrow \delta$ transformation. The 


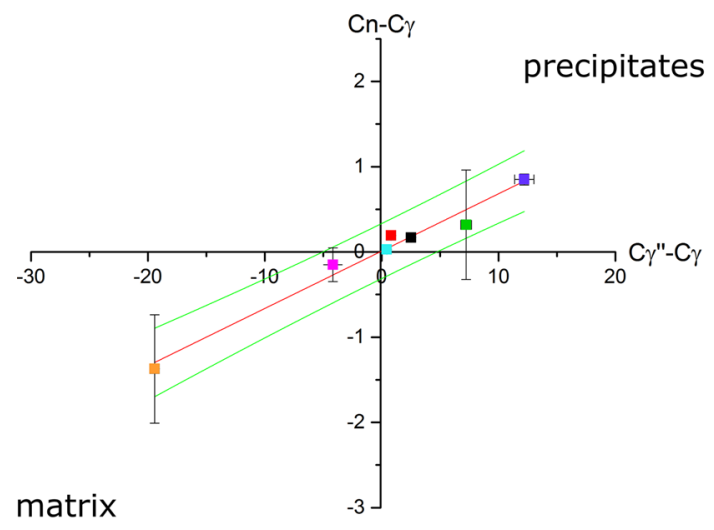

(a)

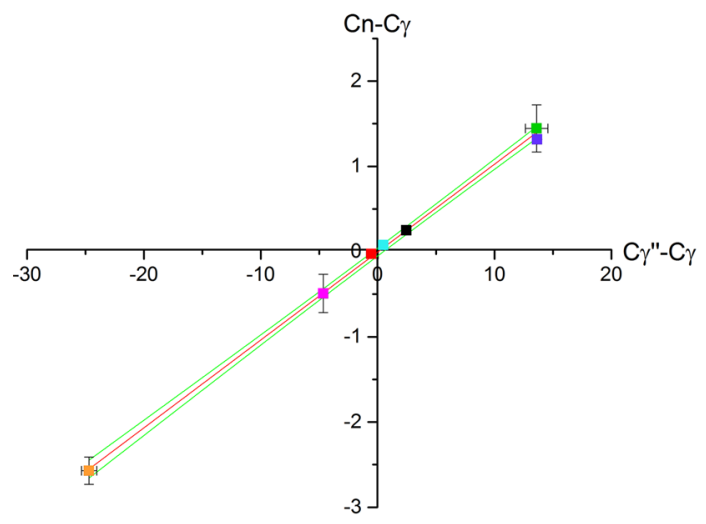

(c)

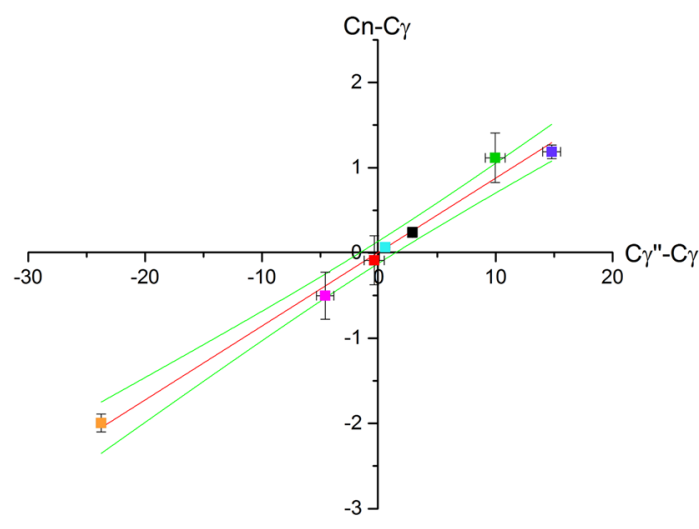

(b)

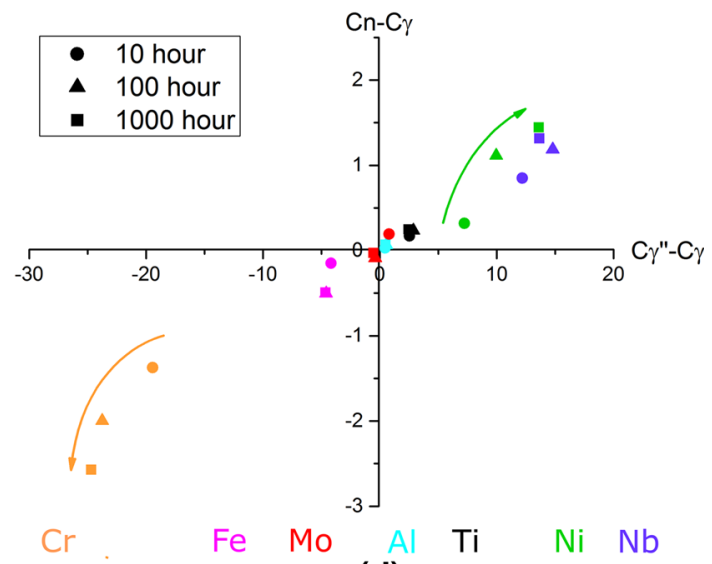

(d)

Fig. 6-Lever rule plots for samples aged for $10 \mathrm{~h}(a), 100 \mathrm{~h}(b)$, and $1000 \mathrm{~h}(c)$ at $650{ }^{\circ} \mathrm{C}$. In $(d)$, the points for the three aging times are plotted on the same graph to allow comparison. A linear fit of the data is shown in red and 95 pct confidence bounds are shown in green on plots (a) through (c) (Color figure online).

orthorhombic intermetallic $\delta$ phase has the stoichiometry $\mathrm{Ni}_{3}(\mathrm{Nb}, \mathrm{Mo})$ and can be distinguished from $\gamma^{\prime \prime}$ via composition, morphology, or crystal structure.

The morphology of the precipitates also evolves with aging time. The precipitates preferentially grow along certain crystallographic directions in order to minimize lattice misfit strain and interfacial energy, resulting in elongation. This morphological orientation of the $\gamma^{\prime \prime}$ also plays a role in the $\gamma^{\prime \prime} \rightarrow \delta$ transformation, since Suave et al. ${ }^{[13]}$ observe that it is $\gamma^{\prime \prime}$ precipitates with similar morphological orientation that coalesce to form $\delta$ phase. This is also in agreement with the mechanism for $\gamma^{\prime \prime} \rightarrow \delta$ transformation proposed by Sudararaman et al. ${ }^{[21]}$ In this, lattice distortion, arising from $\gamma^{\prime \prime}$ phase formation, leads to creation of stacking faults within $\gamma^{\prime \prime}$, which act as nucleation points for the $\delta$ phase. The $\delta$ phase then develops in the $\gamma$ matrix along the three close-packed directions of the $\gamma^{\prime \prime}$ phase, until it intersects with another $\gamma^{\prime \prime}$ precipitate.

The TTT curve produced by Suave et al., ${ }^{[13]}$ and displayed in Figure 9, indicates that samples aged for 1000 hours at $650{ }^{\circ} \mathrm{C}$ are on the boundary of the $\delta$ precipitation domain. Further work is needed to investigate the mechanism underpinning the $\gamma^{\prime \prime} \rightarrow \delta$ transformation. For example, TEM could be used to determine the crystal structure of the precipitates formed over longer aging durations, which would distinguish between the orthorhombic crystal structure of the $\delta$ phase and the $\mathrm{DO}_{22}$ crystal structure of $\gamma^{\prime \prime}$. Accompanying APT of the precipitates could be used to monitor any compositional changes that occur as a result of the phase transformation.

It can be seen from Figure 8 that hardness and volume fraction of $\gamma^{\prime \prime}$ both increase with aging time. This is in agreement with the literature, where increasing hardness was attributed to increased $\gamma^{\prime \prime}$ volume fraction, ${ }^{[14,23]}$ and as mentioned demonstrates the ability of nanoscale APT data to inform about the change in mechanical properties of an alloy that result from phase transformation or phase precipitation. The same trend of increasing hardness with aging time is seen in the measurements by Suave et al. ${ }^{[14]}$ up to aging temperatures of $900{ }^{\circ} \mathrm{C}$. This demonstrates that annealing treatments applied in this temperature range are likely to cause hardening as a result of $\gamma^{\prime \prime}$ precipitation. 


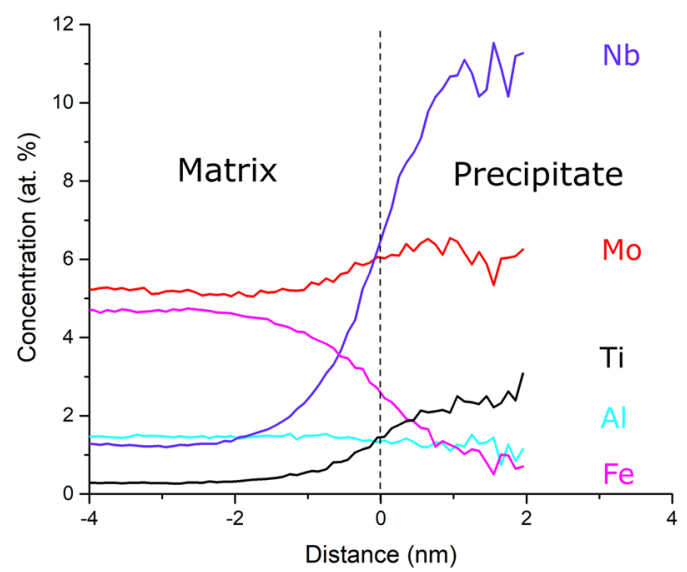

(a)

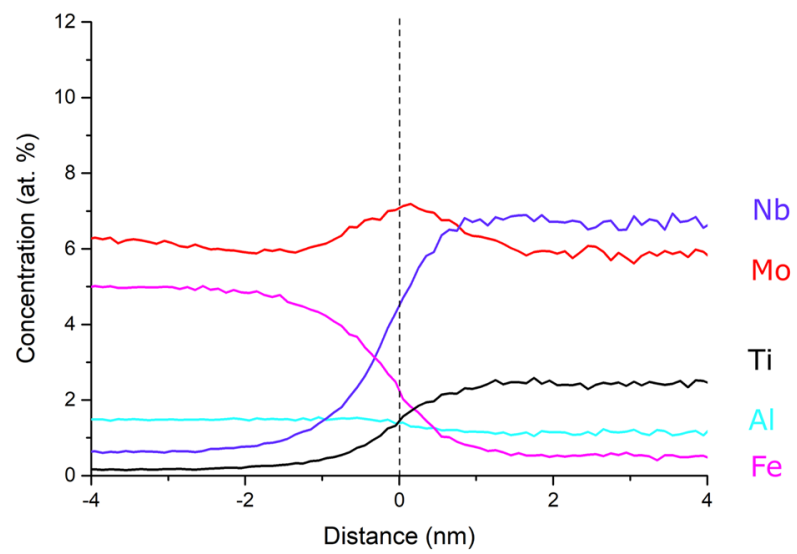

(c)

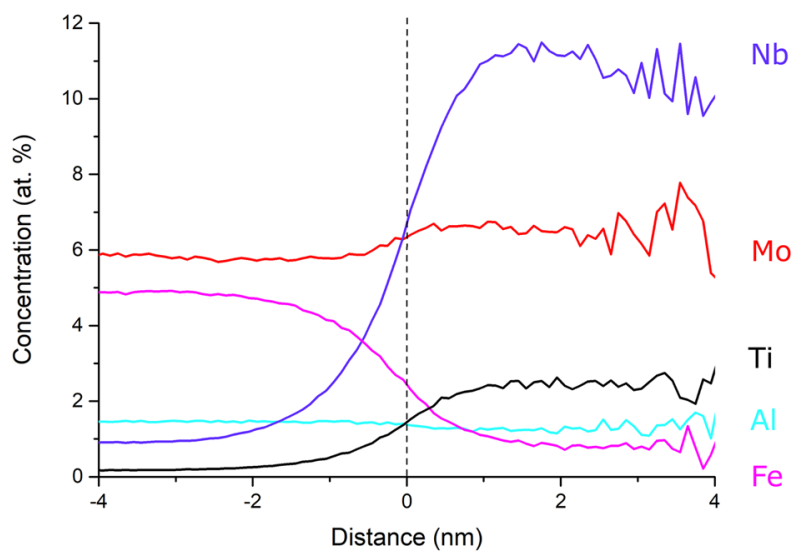

(b)

Fig. 7-Proxigram analyses highlighting change in composition across the matrix- $\gamma^{\prime \prime}$ precipitate interface for the 10 -h $(a)$, 100-h $(b)$, and 1000 -h (c) samples, aged at $650^{\circ} \mathrm{C}$. The dotted line indicates the position of the interface defined by the isoconcentration surface. The proxigrams in (a) and (b) were created using a 4.5 at. pct $\mathrm{Nb}+\mathrm{Ti}$ isoconcentration surface, whereas the proxigram in (c) was created using a 4 at. pct isoconcentration surface.

Table II. $\gamma^{\prime \prime}$ Precipitate and Matrix Compositions as a Function of Aging Time

\begin{tabular}{|c|c|c|c|c|c|c|c|}
\hline Aging Time (h) & $\mathrm{Ni}$ & $\mathrm{Cr}$ & $\mathrm{Fe}$ & Mo & $\mathrm{Nb}$ & $\mathrm{Al}$ & $\mathrm{Ti}$ \\
\hline \multicolumn{8}{|c|}{ Precipitate Composition (At. Pct) } \\
\hline 10 & 67 & 8.1 & 0.43 & 6.3 & 14 & 1.0 & 2.8 \\
\hline 100 & 69 & 4.4 & 0.36 & 5.3 & 16 & 1.1 & 3.1 \\
\hline 1000 & 72 & 4.0 & 0.28 & 5.1 & 15 & 1.0 & 2.6 \\
\hline \multicolumn{8}{|c|}{ Matrix Composition (At. Pct) } \\
\hline 10 & 59 & 28 & 4.6 & 5.5 & 1.2 & 0.53 & 0.20 \\
\hline 100 & 59 & 28 & 5.0 & 5.7 & 1.0 & 0.49 & 0.18 \\
\hline 1000 & 58 & 29 & 4.9 & 5.7 & 0.9 & 0.49 & 0.17 \\
\hline
\end{tabular}

\section{CONCLUSIONS}

This study has characterized the formation and evolution of $\gamma^{\prime \prime}$ precipitates during aging in the nickel superalloy Inconel 625. The following conclusions can be drawn:

1. Precipitation of $\gamma^{\prime \prime}$ occurs after only one hour of aging at $700{ }^{\circ} \mathrm{C}$, which is markedly shorter than the aging time reported in the current literature. ${ }^{[13]}$
2. The evolution of the precipitates as aging progresses may indicate $\gamma^{\prime \prime} \rightarrow \delta$ transformation, supported by several pieces of information:

- There appears to be segregation of molybdenum to the precipitate-matrix interface, which could indicate a loss of $\gamma^{\prime \prime}$ precipitate coherency, and thus indicate the start of a $\gamma^{\prime \prime} \rightarrow \delta$ transformation.

- The morphology of the $\gamma^{\prime \prime}$ changes from spherical to lenticular during aging, in agreement with 


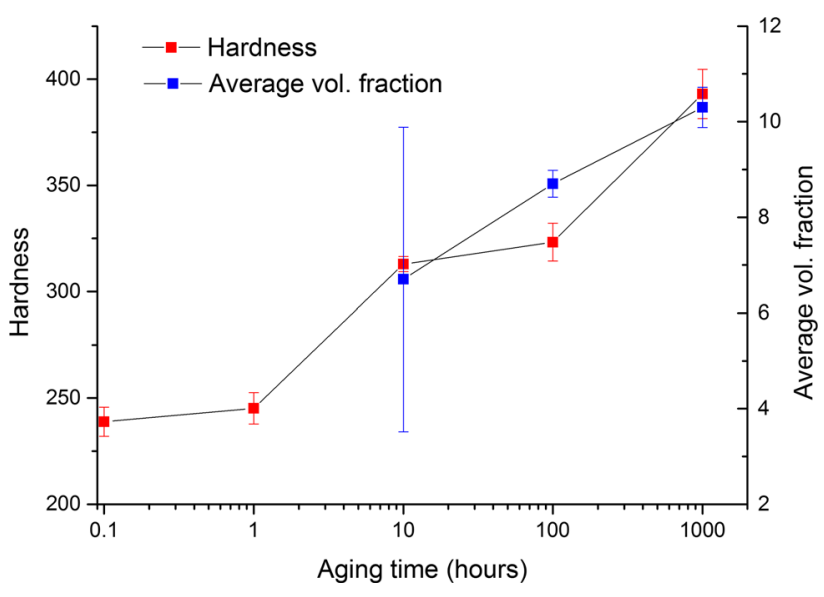

Fig. 8-Plot of volume fraction and hardness of $\gamma^{\prime \prime}$ precipitates as a function of aging time at $650{ }^{\circ} \mathrm{C}$. Error bars show the standard deviation in the respective measurements (Color figure online).

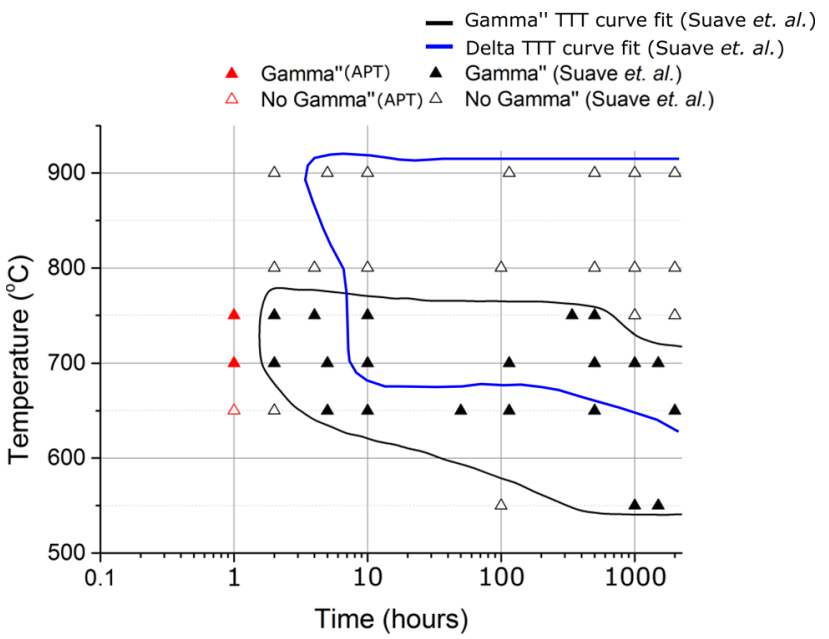

Fig. 9-TTT curve showing points and fit determined by Suave et al. $^{[13]}$ (black), and points determined in this study (red) (Color figure online).

the mechanism for the $\gamma^{\prime \prime} \rightarrow \delta$ transformation proposed by Sudararaman et al. . $^{[21]}$

- The matrix becomes enriched in Mo, and the precipitates depleted in Mo at long aging times, which could be indicative of the lattice distortion that arises in the $\gamma^{\prime \prime}$ phase prior to the $\gamma^{\prime \prime} \rightarrow$ transformation. ${ }^{[22]}$

3. The formation and growth of $\gamma^{\prime \prime}$ precipitates increases the material hardness by approximately 40 pct for an as-received sample compared to a sample aged for 1000 hours at $650^{\circ} \mathrm{C}$.

4. Niobium and titanium, elements which have been shown to segregate at oxide interfaces, ${ }^{[24]}$ are being depleted from the matrix to form $\gamma^{\prime \prime}$ precipitates at markedly shorter aging times than previously reported. This could cause unexpected changes to the corrosion resistance of the alloy when operating in a corrosive exhaust environment. Further work is needed to establish how precipitates formed during aging influence oxide formation.

\section{ACKNOWLEDGMENTS}

Authors acknowledge EPSRC support via EP/ M022803/1. James Famelton is gratefully acknowledged for creation of the Matlab scripts used to produce Figure 3(b). The research materials supporting this publication can be accessed by contacting hazel.gardner@materials.ox.ac.uk.

\section{OPEN ACCESS}

This article is distributed under the terms of the Creative Commons Attribution 4.0 International License (http://creativecommons.org/licenses/by/4.0/), which permits unrestricted use, distribution, and reproduction in any medium, provided you give appropriate credit to the original author(s) and the source, provide a link to the Creative Commons license, and indicate if changes were made.

\section{REFERENCES}

1. C.T. Sims: Superalloys, 1984, vol. 1984, pp. 399-419.

2. H.L. Eiselstein and D. J. Tillack, in Superalloys 718, 625 and Various Derivatives, 1991, pp. 1-14.

3. F. Curà, A. Mura, and R. Sesana: Int. J. Automot. Technol., 2012, vol. 13 (4), pp. 629-36.

4. L. Piancastelli, L. Frizziero, S. Pica, and G. Donnici: $A R P N J$. Eng. Appl. Sci., vol. 11 (3), 2016.

5. F. Weng, H. Yu, C. Chen, and K. Wan: Mater. Manuf. Process., 2015, vol. 30 (11), pp. 1364-69.

6. S. Cruchley, H.E. Evans, M.P. Taylor, M.C. Hardy, and S. Stekovic: Corros. Sci., 2013, vol. 75, pp. 58-66.

7. H. Nagai and M. Okabayashi: Trans. Jpn. Inst. Met., 1981, vol. 22 (10), pp. 691-98.

8. X. Xie, J. Dong, G. Wang, W. You, J. Du, C. Zhao, Z. Wang, and T. Carneiro: Proc. Int. Symp. Superalloys Var. Deriv., 2005, vol. 3 , pp. $287-98$.

9. L. Mataveli Suave, J. Cormier, D. Bertheau, P. Villechaise, A. Soula, Z. Hervier, and F. Hamon: Mater. Sci. Eng. A, 2016, vol. 650 , pp. $161-70$.

10. J.F. Radavich and A. Fort, in Superalloys 718,625 and Various Derivatives, 1994, pp. 635-47.

11. S. Floreen, G.E. Fuchs, and W.J. Yang, in Superalloys 718, 625, 706 and Various Derivatives, 1994, pp. 13-37.

12. J.R. Crum, M.E. Adkins, and W.G. Lipscomb, Natl. Assoc. Corros. Eng., 1986.

13. L.M. Suave, J. Cormier, P. Villechaise, A. Soula, Z. Hervier, D. Bertheau, and J. Laigo: Metall. Mater. Trans. A, 2014, vol. 45A, pp. $2963-82$.

14. L.M. Suave, D. Bertheau, J. Cormier, P. Villechaise, A. Soula, Z. Hervier, and J. Laigo: MATEC Web Conf., 2014, vol. 14, p. 21001.

15. B. Gault, M.P. Moody, J.M. Cairney, and S.P. Ringer, Atom Probe Microscopy. Springer, 2012.

16. G. Kothleitner, M.J. Neish, N.R. Lugg, S.D. Findlay, W. Grogger, F. Hofer, and L.J. Allen: Phys. Rev. Lett., 2014, vol. 112 (8), pp. 1-5.

17. D.B. Williams and C.B. Carter: Transmission Electron Microscopy: A Textbook for Materials Science, 2nd ed., Springer, Berlin, 2009. 
18. F. Vander Voort George: Metallography Principles and Practice, ASM International, Illinois, 1999.

19. D.A. Porter and K.E. Easterling, Phase Transformations in Metals and Alloys, 2nd ed. Nelson Thornes Ltd, 1992.

20. E.A. Lass, M.R. Stoudt, M.B. Katz, and M.E. Williams: Scripta Mater., 2018, vol. 154, pp. 83-86.

21. M. Sundararaman, P. Mukhopadhyay, and S. Banerjee: Metall. Trans. A, 1988, vol. 19A, pp. 453-65.
22. X. Xing, X. Di, and B. Wang: J. Alloys Compd., 2014, vol. 593, pp. 110-16.

23. G.P. Dinda, A.K. Dasgupta, and J. Mazumder: Mater. Sci. Eng. A, 2009, vol. 509 (1-2), pp. 98-104.

24. S. Pedrazzini, E.S. Kiseeva, R. Escoube, H.M. Gardner, J.O. Douglas, A. Radecka, P.M. Mignanelli, G.M. Hughes, G. Chapman, P.D. Edmondson, H.J. Stone, D. de Lille, and P.A.J. Bagot, Oxid. Met., 2017, pp. 1-20. 